\title{
AN APPROACH FOR HYDRO-MORPHOLOGICAL MONITORING OF RIVER WATER BODIES
}

\author{
Iulia LUPU', Marinela MOLDOVEANU, Ruth PERJU, Andreea C. GALIE
}

\begin{abstract}
An approach for hydro-morphological monitoring of river water bodies. Historically, the "freshwater quality" was assessed in terms of chemical and/or pollution status. Later on, the concept of "freshwater quality" has been extended to incorporate a full range of physical, chemical, hydromorphological and biological features. In Europe, the process of monitoring rivers' hydro-morphological features has been enhanced as a result of the Water Framework Directive (WFD) requirements. The Directive 2014/101/EC amending the Annex V of WFD requires to take into account the 'guidance standards' to monitor and assess hydro-morphology using a comprehensive and particularized set of hydro morphological features of rivers. This standards provide a general framework concerning how and what to monitor in terms of rivers' hydromorphology, namely what should be the elements observed, how should the field surveys be planed and accomplished, how should the results be interpreted and presented. The paper presents the steps and issues encountered in defining the set of hydro-morphological features particularized for Romania, as well as the rules and criteria for defining the survey units within the surface water bodies, in terms of location and dimension. The proposed approach takes into account the present state of rivers' monitoring activity and the current designation of surface water bodies, at national level. In this regard, the establishment of the survey units is considered dependent of the position of existing monitoring points (gauging stations, quality monitoring sites, auxiliary gauging sites). In addition, the paper presents the proposed parameters to monitor the hydro-morphological features for the three zones of surface water bodies (channel, river banks and floodplain) defined/established in WFD standards. As an innovative element for Romanian hydro-morphological monitoring, the characterization of the morphological features along the river is highlighted. This research could be the basis for an integrated approach concerning the monitoring and assessment of rivers' ecological status, as well as for the development of a survey unit protocol for recording the changes of specific hydrological and morphological features of rivers/water bodies.
\end{abstract}

Keywords: rivers, hydro-morphological features, survey unit, survey unit protocol

\section{INTRODUCTION}

Aquatic ecosystems management involves the interaction of two key elements: an intensive monitoring process and the application of appropriate methods to assess the water bodies'status. According to the Water Framework

1 National Institute of Hydrology and Water Management, Bucharest, Romania, e-mail: iulia.lupu@hidro.ro; marinela.moldoveanu@hidro.ro; ruth.perju@hidro.ro; andreea.galie@hidro.ro 
Directive (WFD), the objective of monitoring is to establish an ecological status overview within each River Basin District and also to classify all surface water bodies into one of five classes.

As one of the element that defines ecological status is "hydro morphology", the consideration of hydrological and morphological features of rivers in monitoring programs has become a need not only for implementing the WFD but also for nature conservation purposes, helping in the management and restoration of rivers.

Regarding surface water monitoring process the WFD was amended in 2014 by Directive 2014/101/EC which modify the Annex V section 1.3.6. Standards for monitoring of quality elements. Therefore, according to the new amendments, the hydro-morphological monitoring of rivers should be in accordance with the international standard EN 14614/2004 Water quality Guidance for assessing the hydromorphological features of rivers in all Member States.

The EN 14614/2004is a standard survey protocol for recording the physical features of river channels, banks, riparian zones and floodplains. Dividing rivers into reaches and unit survey is fundamental for the survey strategy. The scale of surveys is also important and fixed or variable lengths are recommended according to the degree or morphological uniformity. For a comprehensive overview of river hydromorphology the standard recommends a list of hydromorphological features grouped within 10 categories that cover the three zones of the river: (a) channel; (b) riverbanks/riparian zone; (c) floodplain.

Taking into account the new legislative requirement and also the current monitoring activity (including hydrometric one), the aim of this paper is to present an approach that could be used for the hydro-morphological monitoring of river water bodies in Romania. We particularly address the following issues: (i) defining the survey units within the river water bodies (location and dimension) and (ii) the set of hydro-morphological features for the river monitoring activity.

\section{MATERIAL AND METHODS}

One of the issues tacked within the paper is defining the survey units within the river water bodies namely location and dimension.

The size and location of survey unit (SU) is based on the following criteria:

- the three zones of the river according EN 14614/2004;

- hydrometric and water quality monitoring networks;

- the river water bodies delineation;

- the Methodology for hydromorphological assessment of rivers (Annex 6.1.2.A, Romanian River Management Plan, 2015).

The SU dimensions were proposed in order to cover the three zones of the river mentioned in the standard EN 14614/2004. Therefore, the three zones of the river that will be analyzed in the field surveys are minor river bed, river bank (as part of the riparian flooded zone) and riparian flooded zone (Figure 1). 


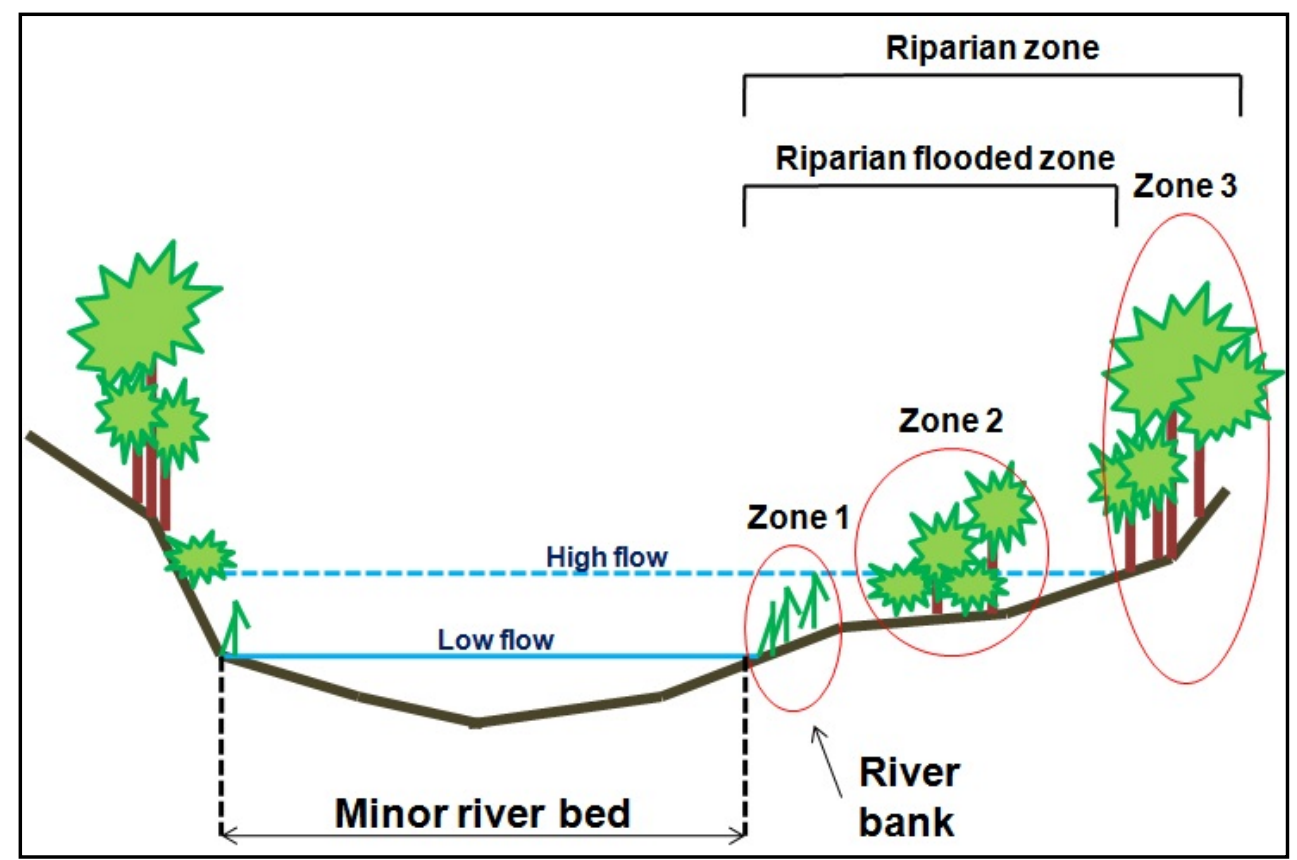

Fig. 1. The three river zones: minor river bed, river bank (as part of the riparian flooded zone) and riparian flooded zone

Regarding the location of the SU, they will be placed in the vicinity of hydrometric stations (including satellite sections) and water quality monitoring sections.

Within the SU a set of hydro-morphological features will be monitored using ten groups of parameters.

\section{RESULTS AND DISCUSSIONS}

The SU is a river sector within a river water body from which hydromorphological data are collected during field survey. The length of SU is fixed - $500 \mathrm{~m}$ (250 upstream and $250 \mathrm{~m}$ downstream hydrometric stations/water quality monitoring sections). The SU lateral survey boundaries (riparian zone width) are variable covering all floodplain features. The delineation of the riparian zone (type-specific width), was established by the Rivers Basin Authorities for all river water bodies for the second Romanian River Management Plan taking into account the guidelines of Methodology for hydromorphological assessment of Romanian rivers. 


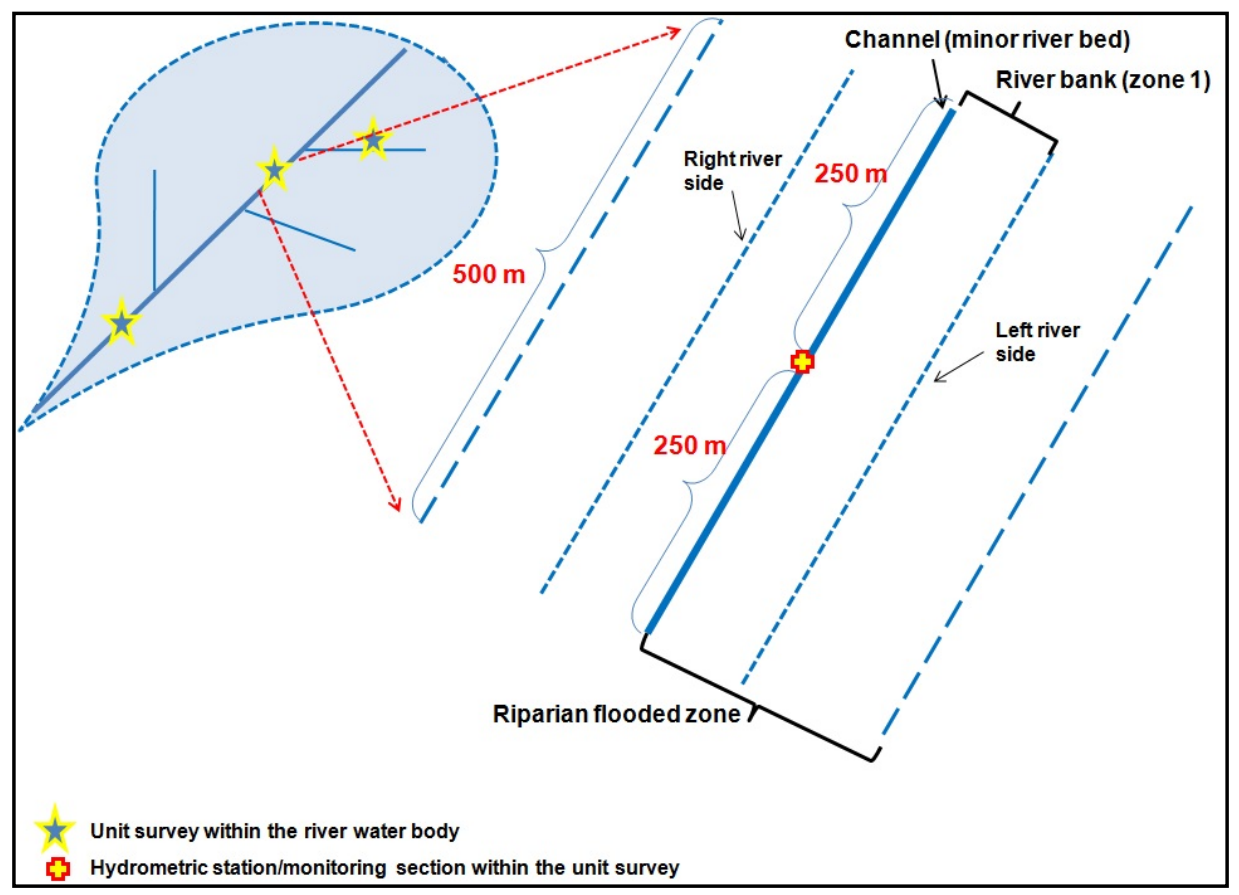

Fig. 2. Survey Unit

As the locations of SU are depending on the hydrometric stations/water quality monitoring sections locations, there are many possible cases within the river water bodies (Figure 3).

The hydromorphological survey is based on the consideration of ten groups of parameters listed in table 1.

if the river water body has one hydrometric station in this case the hydromorphological data will be collected from one SU located in the hydrometric station area

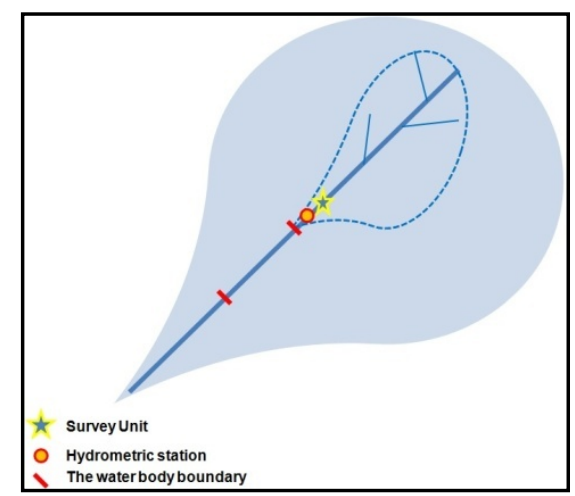


if the river water body has one hydrometric station with monitoring section, in this case the hydromorphological data will be collected from one SU located in the hydrometric station/monitoring section area.

if the river water body has two hydrometric stationsand one monitoring section (in the area of hydrometric station), in this case the hydromorphological data will be collected from two SU: one in the hydrometric station area and one in the hydrometric station areawhich have monitoring section

if the river water body has one monitoring section, the hydromorphological data will be collected from one SU located in the monitoring section area.

if the river water body has no hydrometric station or monitoring section, the SU will be a geomorphologic and hydrologicrepresentative river sector
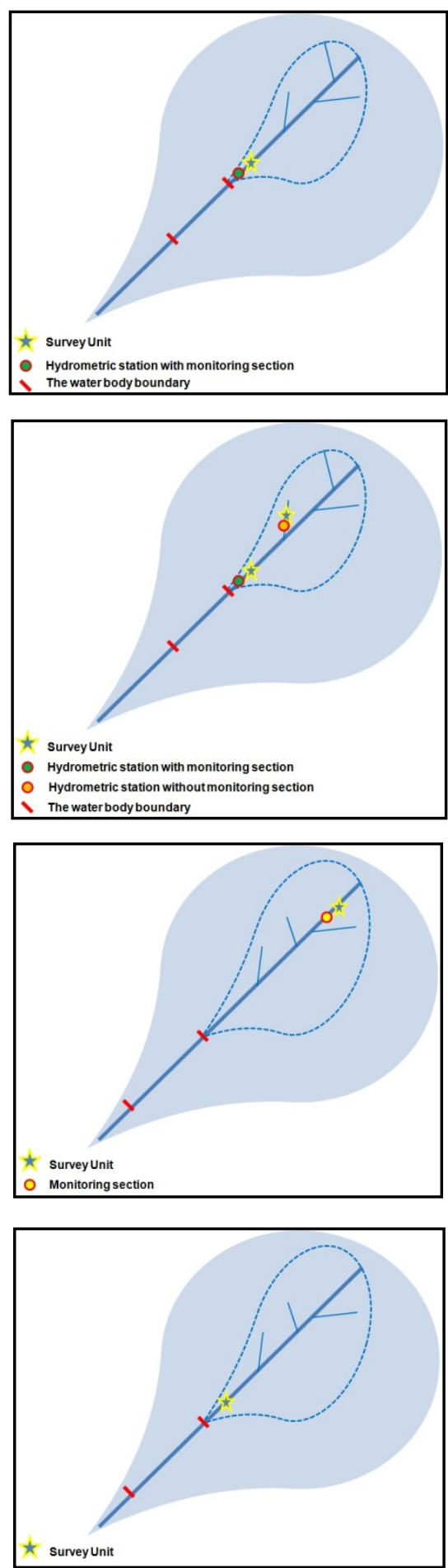

Fig. 3. Possible cases of the SU locations within a river water body 


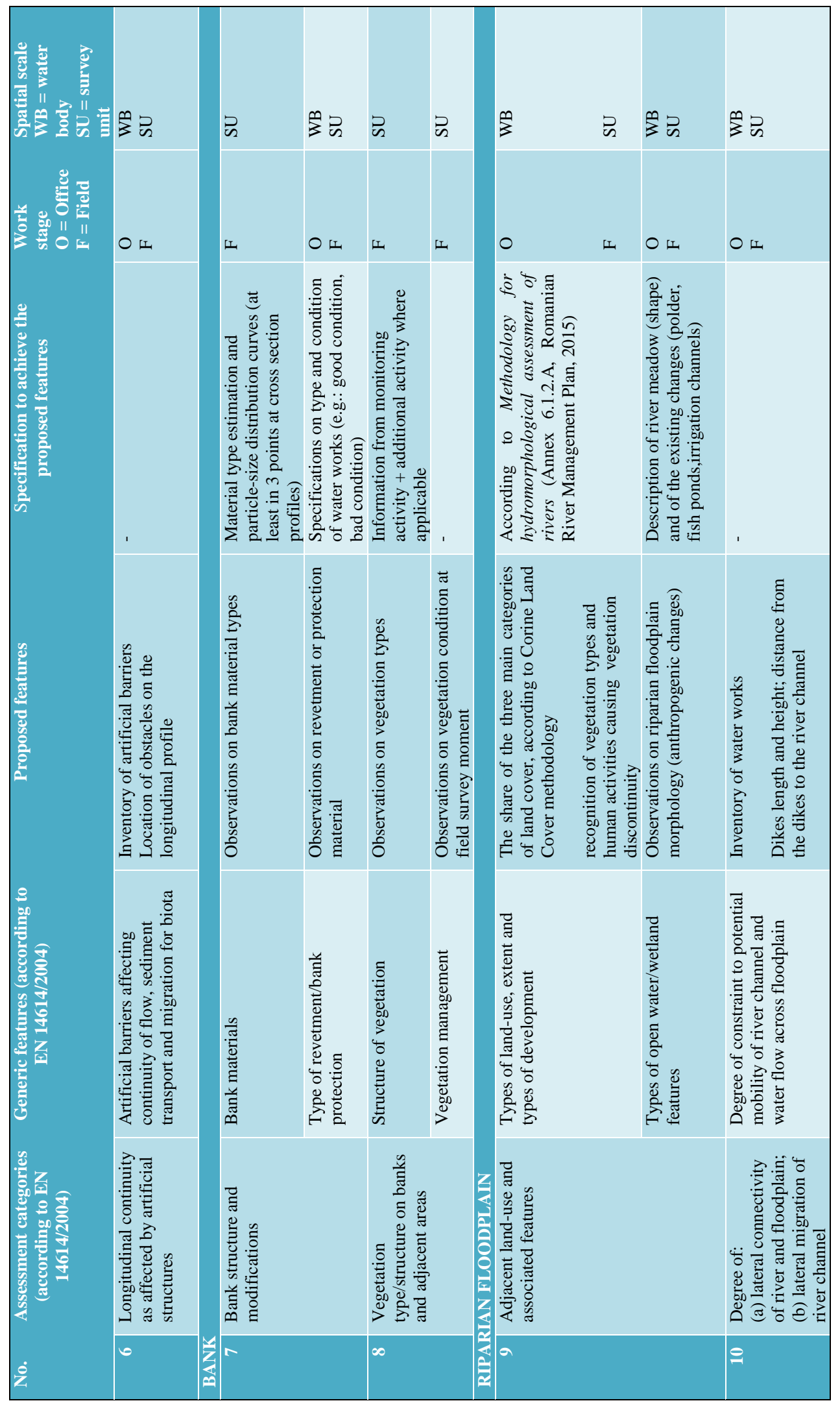




\section{CONCLUSIONS}

The length of SU is fixed - $500 \mathrm{~m}$. The SU lateral survey boundaries are variable covering all floodplain features.

There are many possible cases within the river water bodies when one wants to establish a SU taking into account the locations of current hydrometric stations/water quality monitoring sections.

The hydromorphological survey should consider the European standards included within WFD.

Taking into account that the monitoring of water quality means a periodical update for deriving a true trend of water quality, the approach presented within this paper might lead to rethinking of hydrometric activity within Romania.

Testing the set of hydro-morphological features on representative water bodies for each river basin and the development of a survey unit protocol for recording the changes of specific hydrological and morphological features are crucial.

\section{REFERENCES}

1. *** (2016) Guide for rivers hydrological and morphological parameters in accordance with the updated annex $V$ of the Water Framework Directive 2000/60/EC, National Institute of Hydrology and Water Management.

2. *** (2004), EN 14614/2004 Water quality - Guidance for assessing the hydromorphological features of rivers.

3. *** (2015), Romanian River Management Plan, National Administration "Apele Romane". 